\title{
A story of data won, data lost and data re-found: the realities of ecological data preservation
}

\author{
Alison Specht ${ }^{\ddagger}$, Matthew P. Bolton§, Bryn Kingsfordl, Raymond L. Specht ${ }^{\Uparrow}$, Lee Belbin ${ }^{\#}$ \\ ‡ University of Queensland, Brisbane, Australia \\ $\S$ Corymbia Ecospatial Consultants, Canberra, Australia \\ | Structured Data, Canberra, Australia \\ I Emeritus Professor, Brisbane, Australia \\ \# Atlas of Living Australia, CSIRO, Canberra, Australia
}

Corresponding author: Alison Specht (a.specht@uq.edu.au)

Academic editor: Quentin Groom

Received: 29 Jun 2018 | Accepted: 29 Oct 2018 | Published: 07 Nov 2018

Citation: Specht A, Bolton M, Kingsford B, Specht R, Belbin L (2018) A story of data won, data lost and data refound: the realities of ecological data preservation. Biodiversity Data Journal 6: e28073.

https://doi.org/10.3897/BDJ.6.e28073

\section{Abstract}

This paper discusses the process of retrieval and updating legacy data to allow on-line discovery and delivery. There are many pitfalls of institutional and non-institutional ecological data conservation over the long term. Interruptions to custodianship, old media, lost knowledge and the continuous evolution of species names makes resurrection of old data challenging. We caution against technological arrogance and emphasise the importance of international standards.

We use a case study of a compiled set of continent-wide vegetation survey data for which, although the analyses had been published, the raw data had not. In the original study, publications containing plot data collected from the 1880s onwards had been collected, interpreted, digitised and integrated for the classification of vegetation and analysis of its conservation status across Australia. These compiled data are an extremely valuable national collection that demanded publishing in open, readily accessible online repositories, such as the Terrestrial Ecosystem Research Network (http://www.tern.org.au) and the Atlas of Living Australia (ALA: http://www.ala.org.au), the Australian node of the Global Biodiversity Information Facility (GBIF: http://www.gbif.org). It is hoped that the lessons 
learnt from this project may trigger a sober review of the value of endangered data, the cost of retrieval and the importance of suitable and timely archiving through the vicissitudes of technological change, so the initial unique collection investment enables multiple re-use in perpetuity.

\section{Keywords}

data conservation, data retrieval, legacy data, data curation, long-term data accessibility

\section{Introduction}

An argument without evidence is mere assertion (Parsons et al. 2010). Knowledge of change is fundamental to our custodianship of the Earth's biodiversity. To appreciate and quantify the effects on biodiversity of changes in climate and land use, for example, it is well recognised that we need to call on information from the past and to repeat data collection effort (Lindenmayer and Likens 2009; Jetz et al. 2012; Morris and White 2013; Schimel et al. 2013; Wyborn 2015; Kissling et al. 2017). There are many challenges, however, to realising past data for future use.

The scale of past data collections is often beyond today's means so replication may be nearly impossible. Cook's various explorations of the Pacific, Humbolt's expedition to South America, and Darwin's voyages in the Beagle required great planning, the assembly of many personnel across many disciplines, and occurred over great distances and time. Data-collecting expeditions of similar scale would be prohibitively expensive to launch in modern times (Powney and Isaacs 2015). The wealth of data acquired on such expeditions continues to inform our understanding of the world and how it functions, and it could be argued they are even more valuable in consequence of their very unrepeatability.

These famous expeditions are mere examples of an abundance of organised data collections made over the centuries. We benefit from only a fraction of this knowledge as a huge mass of data from the filing cabinets and the computers of scientists and research teams, despite the best intentions, are poorly described and managed, unavailable, or completely lost (Nordling 2010; Vines et al. 2014). The longer the time-span since an initial collection effort, the harder (and more costly) these data are to retrieve (Vines et al. 2014).

Routine long-term data collection and its ongoing management and conservation is often a low priority in policy-driven government departments, while physical and digital data storage has been increasingly 'rationalised' as data custodians have been made redundant and agencies are either downsized, re-structured or abolished (Pickrell 2017; Phillips 2017). Amongst the benefits of archiving data for future use is that new and totally unanticipated uses and value can be found for them. This is well illustrated by the later use of whale catch data collected for taxes and excise duty in the nineteenth and early twentieth centuries for the detection of the effect of climate change in the Southern Ocean (de la Mare 1997). This re-use was only made possible because the data were openly 
available and fully described. The whalers could never have anticipated that their catch data would be used to detect evidence of climate change. Modern intellectual property laws structured to protect rights to information, however, can discourage or prevent analyses of this nature. Sadly, many data owners are fearful of their data being used for purposes other than those for which it was originally collected (Tenopir et al. 2011; Specht et al. 2015; Mills et al. 2015; Mills et al. 2016). The advent of metadata has at least exposed that data exist, even if they may not currently be publicly available (Bagley 1968). Initiatives such as data carpentry and the integration of mandatory data management plans in research grant applications have increased the acceptance of data publication amongst scientists as something in which they can engage (Teal et al. 2015; Curty et al. 2017). Scientists will always need support in the process of data publication as they need to focus on their primary research (Lynch 2008; Martin et al. 2017).

Recovery of past data is a difficult challenge depending on how the data have been stored (see Specht et al. 2015). Data storage systems have changed profoundly since the beginning of the digital age. Punch cards and paper tape have been superseded by magnetic tape (in a myriad of formats), floppy discs, hard discs, optical discs, flash drives and cloud storage. Even when stored digitally, changes to storage media and formats require continual inspection and potential intervention, without which the data are put at risk of loss (Bergeron 2001; Vines et al. 2014; Michener 2016). Devices that read obsolete media require connection with old cables to old computers and software. Such systems are increasingly hard to find or adapt to modern systems. Even if the media are supported, a data file written in a particular format may not be readable with newer software and, in some cases, even with later version releases of the same software (for example the various versions of Microsoft Excel). Documents written using Wordstar or SuperCalc on 5.25-inch floppy discs using a CP/M operating system (the original documentation for our case study), although stored, are lost for most practical purposes. Some data may need to be recovered from hard copy printouts using, for instance, optical character recognition (OCR), but this recovery process, even if possible, is extremely costly in time and money.

Data may further be broken up across multiple files, in various formats, and may violate basic principles of current best-practice data structures. Although the principles of relational database design were well established by the 1980s (Codd 1970), the computers and tools available to ecologists until recently were often unreliable and expensive or difficult to use (e.g. 1022 on a DEC PDP-10 mainframe).

Data communities (e.g. Data Science Central: https://www.datasciencecentral.com and the Research Data Alliance: https://www.rd-alliance.org), data repositories (e.g. PANGAEA: htt ps://www.pangaea.de; the Australian Antarctic Data Centre: https://data.aad.gov.au; the Knowledge Network for Biodiversity: https://knb.ecoinformatics.org; DRYAD: https:// datadryad.org; the Atlas of Living Australia and the Terrestrial Ecosystem Research Network) and data management support initiatives such as DataONE have been developed to facilitate systematic data sharing and long-term data preservation by scientists. Such good intentions will require, however, consistent advocacy and ongoing monitoring. 
Ecological data present a particular challenge for management and preservation because they are:

- $\quad$ geographically, taxonomically and temporally unique (Ellison 2010);

- $\quad$ heterogeneous (Reichman et al. 2011; Wieczorek et al. 2012);

- frequently disaggregated and held in the hands of individuals and small organisations (Heidorn 2008).

The heterogeneity of ecological datasets is arguably a consequence of the nature of the profession. A survey of 751 Australian ecologists in 2011 produced more than 160 selfidentified sub-categories of 'ecologist' (Keniger and Specht 2012) and ecologists typically collect and integrate different types of data simultaneously (Hampton et al. 2013; Garnier et al. 2017). The distance between data collectors and those skilled in delivering the data is considerable (Campbell et al. 2015). We propose that the arduous and costly nature of ecological data collection, reliant on individual effort in remote and often perilous locations, further contributes to a sense of personal ownership of research outputs and a reluctance to share hard-won data.

Although great strides have been made in the past twenty years towards the routine publication of data, properly described, protected and archived for future use, the recovery of past ecological data remains in its infancy. Synthesis centres such as NCEAS, CESAB, sDiv, John Wesley Powell and ACEAS (see www.synthesis-consortium.org) support ecological analyses that only use existing data (Curty et al. 2017). In these centres, small groups of people organise and synthesise existing data for analysis, and release new, cleaned datasets (e.g. Haberle et al. 2014; Sosef et al. 2017). Such work is focussed on defined ranges of data relating to a particular question and, although immensely valuable both for training scientists in data recovery and in the release of datasets that might otherwise have been lost, synthesis groups generally work at a project-by-project level.

We present a case study of a continental set of ecological data that has had a long history of recovery and digitisation: once in the 1980-90s and again this century. Through this example, we illustrate the challenges imposed by changing norms of publication and technology, the benefits of deposition in a curated repository and provide some guidance for data management.

\section{The original data collection}

The chosen case study arose at the dawn of 'Big Data in Biology' sensu Aronova et al. (2014), when the ability of computers to aggregate and analyse large amounts of data was becoming a reality. A study had been made of the conservation status of vegetation formations across Australia and New Guinea (Specht et al. 1974), using an assessment method developed in Australia (Specht and Cleland 1963; Frankenberg 1971) and adopted by the Conservation Section of the International Biological Programme (Peterken 1967). These assessments were generated through expert opinion, considered appropriate for the time, but were limited by gaps in information and bias. With the advent of mainframe 
computers by the mid-1970s, an objective approach to the classification of major plant communities became possible, and a grant from the Australian Heritage Commission was obtained for that purpose. Thus, a new project commenced to repeat and update the 1974 assessment taking advantage of the new analytical algorithms, which resulted (inter alia) in the 'Conservation Atlas of Plant Communities in Australia' (Specht et al. 1995).

Published data in refereed journal articles and 'grey' literature (i.e. government and research reports) were retrieved in hard copy (Fig. 1A) and full species lists and metadata (vegetation structure, soil type and landscape descriptions) were extracted (Fig. 1B). Partial lists and those without 'accurate' geo-references (for the time) were rejected. This was a major task, requiring manual extraction and evaluation by the supervising team and data entry by postgraduate students: 711 ecological surveys incorporating 4088 floristic lists were assembled.

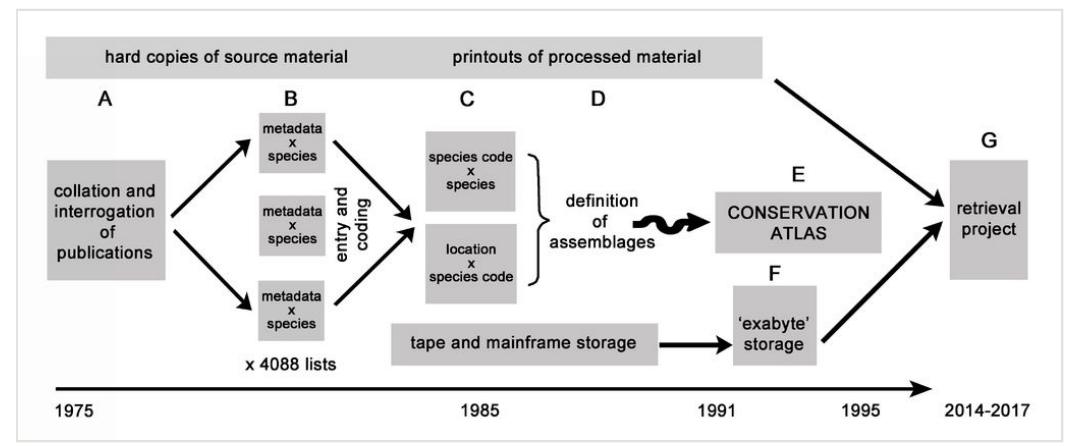

Figure 1. doi

The workflow from collation of original documents $(A)$ through the publication of the 'Conservation Atlas' (E) to the retrieval project (G). The first step was to extract and digitise data from written publications (A-B). Due to the computing limitations of the time, it was necessary to split the data into sub-files (B and $C$ ) for analysis (D) which was the aim of the original project ('The Conservation Atlas' 1975-1995). Storage throughout the Conservation Atlas project was in both hard copy printouts and digital form. The 'mainframe' computers referred to were those from the PDP-10 computer family through the University of Queensland computer centre. The magnetic tapes were used as backup storage from the PDP-10s and the Exabyte tape was used to store the data from the magnetic tapes at the end of the Conservation Atlas project.

Note: Letters are used to facilitate reference to the figure from the text. The temporal axis is not to scale.

Due to the computational limitations of the time, the data were organised according to vegetation formation (e.g. forests, sclerophyll vegetation, mallee; Specht et al. 1995; Specht and Specht 2013) and each species was given a unique 9-character alphanumeric code to enable data handling and subsequent analysis. These codes necessitated the development of a bespoke system for the creation of two main digital files for each formation: the site metadata (including provenance) with alphanumeric lists of species, and a 'conversion' file for the link between the alphanumeric codes and their full scientific 
names (Fig. 1C). The system for handling the data was standardised in the first three years and the resultant workflow called CAVE (Classification of Australian VEgetation) formed the basis of a procedural manual (Bolton 1985). The last of the raw data were entered and analysed in the early 1990s with species names and metadata information correct at that time. As they were entered, the species lists (with metadata) and analyses were printed for checking and safe-keeping and the data on the PDP-10 family of computers at the University of Queensland were backed up on 9-track magnetic tapes. The compiled data by vegetation formation is shown in Table 1.

Table 1.

Numbers of sites and species in each vegetation formation in the initial project. These numbers include species that occur in more than one vegetation formation.

${ }^{*}=$ Not including introduced species or singletons within the formation; ${ }^{* *}=$ Not including tree species $>10 \mathrm{~m}$ tall

\begin{tabular}{|c|c|c|c|}
\hline Formation & Locations & Communities & Species* \\
\hline Closed forests & $\mathrm{n} / \mathrm{a}$ & 644 & 1,418 \\
\hline Dry scrubs - SE Queensland & 232 & 232 & 475 \\
\hline Dry scrubs - Northern Territory & $\mathrm{n} / \mathrm{a}$ & 1,219 & 559 \\
\hline Eucalypt open-forests and woodlands (tree species) & 201 & 1,275 & 276 \\
\hline Sclerophyll vegetation SW Western Australia & 64 & 172 & 1,761 \\
\hline Sclerophyll vegetation Central and Eastern Australia & 188 & 549 & $2,581^{\star \star}$ \\
\hline Sclerophyll vegetation - heathland and tall shrubland & 136 & 312 & $2,071^{\star \star}$ \\
\hline Alpine vegetation & 73 & 61 & 556 \\
\hline Savannah understorey & 56 & 198 & 1,313 \\
\hline Mallee open-scrub & 28 & 41 & 395 \\
\hline Desert Acacia & 54 & 148 & 1,229 \\
\hline Chenopod shrubland & 30 & 68 & 410 \\
\hline Forested wetlands (including brigalow) & 31 & 36 & 193 \\
\hline Arid wetlands & 20 & 42 & 642 \\
\hline Freshwater swamp vegetation & 80 & 80 & 139 \\
\hline Coastal dune vegetation & 45 & 56 & 315 \\
\hline Coastal wetland vegetation (mangroves and saltmarshes) & $\mathrm{n} / \mathrm{a}$ & 15 & 74 \\
\hline
\end{tabular}

Once entered and organised, the data were analysed to define floristic associations using the non-parametric programmes TAXON (Ross 1984) and TWINSPAN (Hill 1979; https:// www.ceh.ac.uk/services/decorana-and-twinspan). After validation by experts, a total of 921 major plant assemblages were defined (Fig. 1D). Biogeographic regions were derived from these data using the classification programme PATN (Belbin 1994; http://www.patn.com.au ). The distribution of each TWINSPAN assemblage and the biogeographic regions were plotted spatially at $0.5^{\circ} \times 0.5^{\circ}$ resolution using Arc-GIS software together with an 
assessment of the conservation status of each floristic assemblage and published as an Atlas (Specht et al. 1995; Fig. 1E). The original project spanned a period of 20 years (1975 to 1995), involved several scientists and was funded by additional small research grants.

In 1991, when the mainframe computers at the University of Queensland were decommissioned, the data from four of the five magnetic tapes - only readable on the PDPs were transferred to exabyte tape, considered the best option at the time. The information on the fifth tape could not be retrieved. The company making Exabyte tapes ceased operations in 2006 (Fig. 1F). Despite attempts at the time, the raw data contributing to this study were not stored digitally.

Physical copies of the original papers, various analyses and data files were stored in Ray Specht's house when he retired (Fig. 2A-C). The magnetic tapes were stored at Southern Cross University, Lismore, New South Wales, Australia. The 'Exabyte' tapes were stored in two locations some thousands of kilometres apart (with A. Specht, who also had the magnetic tapes, and M.P. Bolton) until the present retrieval project commenced in 2014 (Fig. 1G).

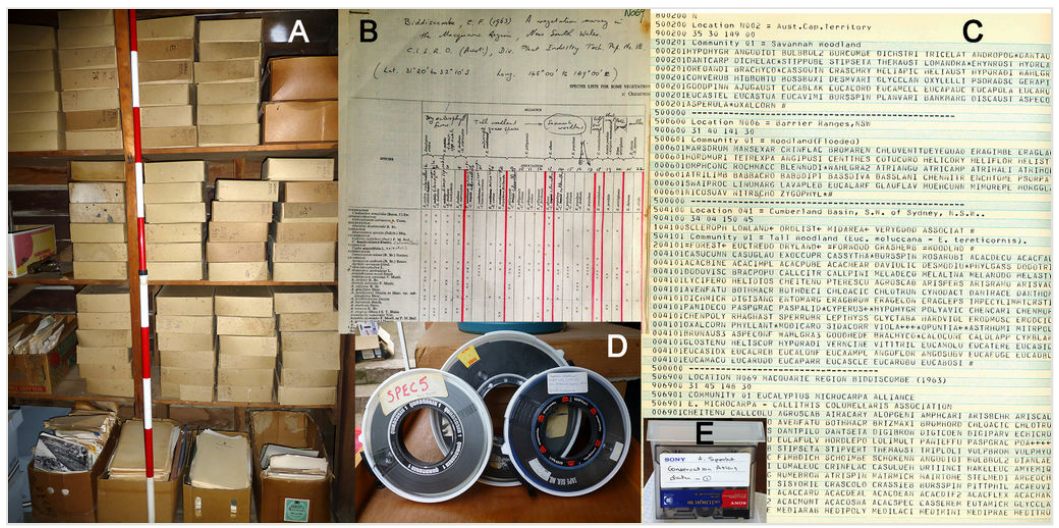

Figure 2. doi

Illustration of the data resources available to the retrieval project: (i) a sample of the boxes of original copies of papers and reports (A), (ii) a table extracted from a publication prepared for data entry (B), (iii) a sample of the hard copy printouts showing alphanumeric lists of species under each location and community (C), (iv) the magnetic tapes on which backups were kept from day to day during the 1980s project (D), and (v) an exabyte tape on to which the data from the magnetic tapes were transferred in $1991(\mathrm{E})$.

\section{Retrieval}

The retrieval project (Fig. 1G) aimed to recover, preserve and deliver the data assembled for the original vegetation assessment project through now-established open biodiversity data repositories. Financial support and some staff time were provided by the Terrestrial 
Ecosystem Research Network (TERN) and the Atlas of Living Australia (ALA), the two repositories identified as most relevant for these data.

The first challenge was to develop a system for checking and updating the species names at the time of the 'Conservation Atlas' data collection. The most efficient and relevant mechanism to do this was through a web-service interface with the ALA (see http:// api.ala.org.au, accessed 3 May 2018) which is the relevant authority for Australian species (see https://www.rbg.vic.gov.au/science/projects/taxonomy/atlas-of-living-australia-nationalspecies-lists-project, accessed 11 December 2017).

The plot-based, species structure of the original data was converted to individual observations of species with freely associated data, such as location, date and time, observer, vegetation classification, source and team comments. We wanted to ensure that no information was lost in re-structuring the data for publication using the widely-supported Darwin Core Standard (Wieczorek et al. 2012). The planned process was as follows :

1. Recover all available data from

- Hard copy

- Exabyte tape

- $\quad$ Other data in digital form (e.g. Excel spreadsheets) (Fig. 3)

2. Design a structure that reflects how the data should be viewed from current perspectives (Fig. 3)

- $\quad$ Site data/metadata (latitude/longitude by vegetation structure by comments) (Fig. 3B)

- $\quad$ Species alphanumeric codes and their associated scientific names

- $\quad$ Sites by species codes (some with multiple communities)

3. Update the species codes/names to current nomenclature (Fig. 3C)

- Use the Atlas of Living Australia's web services (http://api.ala.org.au, accessed 3 May 2018), the National Species Lists and Australian Plant Census (CHAH: https://www.anbg.gov.au/chah/apc) to semi-automate the current identification of species names

- Manually check any ambiguous or missing names

4. Map the fields used in the Conservation Atlas project to the Darwin Core standard (Fig. 3D)

- $\quad$ Collate the terms used in the previous studies

- Determine the intent of the fields

- $\quad$ Find the best equivalent term in the Darwin Core standard

5. Collate and integrate the data

- $\quad$ Produce a list of species observations using the Darwin Core terms at each site (defined by a consensus latitude/longitude) with metadata including vegetation type/structure, source reference details (Fig. 3A) and processing comments.

6. Generate a collection-level metadata record. 


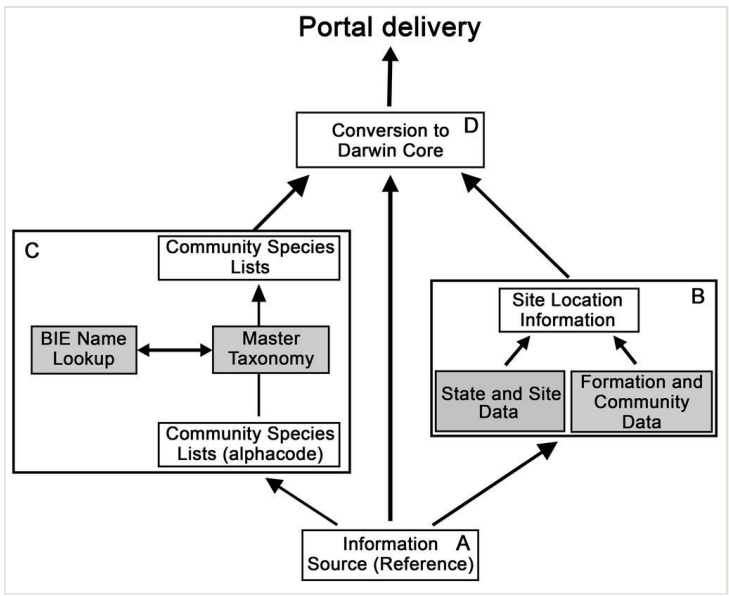

Figure 3. doi

Diagrammatic representation of the workflow for retrieval of data from the original reference files (A). These files were separated into two parts for editing influenced by the 1980s organisation of the data: (i) information on the sites at which data were collected (B), and (ii) the species lists, which were updated through the Biodiversity Information Explorer, BIE (http:// bie.ala.org.au/ws) (C). Once these components were updated, they were re-assembled using DarwinCore standards $(D)$ to enable delivery through a data portal (in this case the Knowledge Network for Biocomplexity, KNB (https://knb.ecoinformatics.org). Ecological Metadata Language (EML) was used to describe the dataset.

The Darwin Core standard (Wieczorek et al. 2012; http://rs.tdwg.org/dwc, accessed 3 May 2018) provides maximum interoperability and is the standard used by the Global Biodiversity Information Facility (GBIF; http://www.gbif.org) and its nodes including the Atlas of Living Australia (ALA). Darwin Core has around 185 fields, more than sufficient to encode the information associated with the Conservation Atlas data. The only other candidate standard applicable to this project would have been Access to Biological Collections Data (ABCD; https://github.com/tdwg/abcd, accessed 3 May 2018), but this standard is far more detailed than required and more applicable to specimen data. Metadata for ecological data are commonly at the collection rather than the record level and the associated standard in wide use is the Ecological Metadata Language (EML; Fegraus et al. 2005). The data were made available through the Knowledge Network of Biocomplexity (see Specht et al. 2018) and are displayed through the Atlas of Living Australia on: https://collections.ala.org.au/public/show/dr8212 (accessed 15 October 2018).

When data retrieval began, the comprehensive computer printouts were the only information source immediately available (Figs 1,2), as the existence of the Exabyte tapes was unknown. One tape was known to have disappeared (despite having been lodged for safe keeping in the steel cabinet of the GIS office of Southern Cross University where the Atlas was produced in 1995) and the other could not be found. Various hard copy data recovery options were therefore initiated, including Optical Character Recognition. While options were being considered, staff from the Australian Centre for Ecological Analysis and 
Synthesis (ACEAS-TERN) led by A. Specht, assisted by R.L. Specht, entered the location details from the printouts into a spreadsheet (Microsoft Excel).

A total of 461 locations (135 of these had multiple survey sites within each broad location) were identified from the paper copies and these provided a checklist and structure for the future data compilation. After locating an Exabyte tape reader (not an easy matter either), we found that the tape was fortunately readable but had overlapping content, containing several different file types including basic species and site data, computer programmes for the original data transformation and intermediate and final analysis results (as had the original magnetic tapes and printouts). As noted previously, most of the basic species and site files were consistently structured and were named according to vegetation formation leading to duplication. While confusing, duplication was far preferable to gaps in data. No data remained in either paper or digital form for the rainforest, dry scrubs, alpine vegetation and coastal wetland vegetation formations. This proved to be a loss of a large proportion of the data originally digitised.

Data on 1390 communities were recovered across the remaining formations, with alphanumeric codes for 9450 taxa and associated metadata. The estimated present cost of repeating the collection of raw data from the 461 locations, including species identification, preservation and documentation, would be conservatively AU\$29 million. The estimated present cost of extracting and digitising the species lists from the initial articles collated would be around AU\$8 million.

\section{The raw data files}

\section{Core data}

The most recent versions of the files were identified relative to the surviving hard copies. The following provides an insight into the complexity of decoding the available files. The digital information was organised (within files by formation) hierarchically: location; source (author); community parameters; and the species codes. Each category was given a control digit to identify the nature of the data following. This provided inputs to (mostly) sequential algorithms programmed in FORTRAN for precise formatting or Pascal for reformatting and quality assurance.

- 800000: an alphanumeric identifier for the state in which the site is found e.g. $\mathrm{N}$ for NSW, P for Northern Territory, Q for Queensland etc.

- 50xxxx: location name, unique code (including state identifier) and source.

- 90xxxx: latitude and longitude

- 5xxxbb: community number (bb) at the location, followed by the description

- 30xxxx: additional comments (not always present)

- 00xxxx: a list of 9-character alphanumeric codes for species occurring in the community. The ninth character was reserved for subspecies and varieties, so in most cases was left blank.

- 500000 -----------------: end of location entry 
The fundamental problem with the data format (Table 2) is that the definition and formatting of the data was conditional on the contents of the number block. It was a format optimised for sequential data processing rather than modern approaches, such as "fields" or attributes containing data. This project reformatted the input data into files with .csv formats, but these are far too complex for this paper.

Table 2.

An example of the core data available from printouts and (mostly) retrieved from Exabyte tapes according to formation and State. These examples are from the forested wetlands and desert acacia formations in New South Wales (N) and the Northern Territory (P).

\begin{tabular}{|c|c|}
\hline $\begin{array}{l}\text { LINE } \\
\text { ID }\end{array}$ & Information \\
\hline 800000 & $\mathrm{~N}$ \\
\hline 503200 & LOCATION N032 = CENTRAL COAST: SYDNEY (PIDGEON 1940) \\
\hline 903200 & 335115113 \\
\hline 503201 & COMMUNITY 01 = FRESHWATER RIVER (COMBINED LIST) \\
\hline 003201 & UTRIAUST UTRIEXOL UTRIBILO VALLGIGA POTAOCHR POTAPERF POTATRIC BRASSCHR \# \\
\hline 003201 & NAJAMARI MYRIPROP PHRAAUST ELEOCHAR* TYPHORIE TYPHDOMI TRIGPROC TRIGSTRI \# \\
\hline 003201 & JUNCPAUC JUNCPALL JUNCPLAN AGROAVEN GAHNIA_ * CASUCUNN MELALINA MELASTYP \# \\
\hline 003201 & CALLSALI EUCAROBU EUCAAMPL CAREX___ * ISOLPROL VILLRENI ALISPLAN RANURIVU \# \\
\hline 003201 & GRATPUBE GOODPANI HYDRPEDU CENTASIA VIOLHEDE PRUNVULG STELFLAC SCHOAPOG \# \\
\hline 003201 & OPLIIMBE BLECINDI ADIAAETH PHILLANU \# \\
\hline 503202 & COMMUNITY 02 = FRESHWATER SWAMPS ON WIND BLOWN SAND (PORT STEPHENS) \\
\hline 003202 & BAUMTERE BAUMARTI TRIGPROC TRIGSTRI PHILLANU LEPIARTI MELAQUIN EUCAROBU \# \\
\hline 003202 & ISOLINUN GRATPEDU DROSSPAT VILLRENI BAUMJUNC SCHOBREV RESTAUST LEPTTENA \# \\
\hline 003202 & RESTTETR SPREINCA BOROPARV EPACOBTU GONOMICR BLECINDI HYDRTRIP SPHAGNUM* \# \\
\hline 003202 & VIOLHEDE \# \\
\hline 500000 & 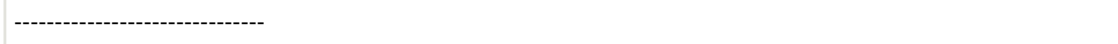 \\
\hline 800000 & $\mathrm{P}$ \\
\hline 503700 & LOCATION P037 = TANAMI DESERT: LAKE SURPRISE, N.T. (MACONOCHIE 1973) \\
\hline 903700 & 201513145 \\
\hline 503701 & COMMUNITY 01 = TUSSOCK GRASS-SEDGE-LAND + TREES \\
\hline 303701 & EUCAPAPU ACACVICT \# \\
\hline 003701 & ABUTOTOC ACACADSU ACACJENS ACACMELL ACACSTIP ACACTENU ALTEANGU ARISBROW \# \\
\hline
\end{tabular}




\begin{tabular}{|c|c|}
\hline 003701 & ARISINAE BERGTRIM BONALINE BRACHOLO BRUNAUS2 BULBBARB CANTATTE CASSCOST \# \\
\hline 003701 & CASSHELM CASSOLIG CASSFILI CLEOVISC CLERFLOR COMESYLV CROTCUNN CROTEREM \# \\
\hline 003701 & CYPEBULB CYPECUNN CYPEHOLO CYPEIRIA DAMPCAND DESMMUEL DICRLEWE DODOPETI \# \\
\hline 003701 & ECTRSCHU ELYTSPIC ERAGLANF ERIAARIS ERIABENT EUCAASPE EUCAPRUI EUCASETO \# \\
\hline 003701 & $\begin{array}{l}\text { EUCATERM EULAFULV EUPHDRUM EUPHWHEE GOODAZUR GOODENIA*GOMPCONI } \\
\text { GREVJUNC \# }\end{array}$ \\
\hline 003701 & GREVWICK HALGSOLA HELIAMBI HIBILEPT HIBISTURC HIBISTURP INDIBREV IPOMMUEL \# \\
\hline 003701 & ISOTATRO LOMALEUC MARSEXAR MELAGLOM MELALASI MELANERV MELHOBLO MELOMADE \# \\
\hline 003701 & MERRDAVE MIRBVIMI MORGFLOR NEPTDIMO PANIAUST PARAMUEL PHYLCARP PHYLHUNT \# \\
\hline 003701 & PHYLRHYT PIMEAMMO PLECPUNG PLUCTETR PLUCTETRT POLYSYNA POLYGALA *PORTFILI \# \\
\hline 003701 & PORTOLER PSORMART PTILARTH PTILASTR PTILCALO RULILOXO SANTLANC SCAEPARV \# \\
\hline 003701 & SCIRLAEV SIDAPLAT STACMEGA SWAIBUR3 SYNATILL TINOSMIL TRIAPILO TRIOPUNG \# \\
\hline 003701 & TRIUGLAU WALTINDI ZORNALBI \# \\
\hline 500000 & 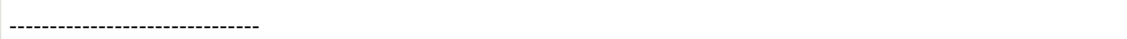 \\
\hline
\end{tabular}

The list of publications, from which the data had been retrieved, was fortunately readable and only required checking and updating. Each citation was given a unique number for the purposes of retrieval (Table 3). Hard copies of most of the source articles that had been obtained for the original project (pre-1995) had been retained so were available to the present authors (Fig. 2). A major component of the retrieval project was to curate the original paper copies, the careful filing of which had been destroyed when R.L. Specht's papers were removed from his University office when he retired. In consequence, sources that were not or were incompletely digitised at the time of the retrieval project will be more easily able to be scanned and shared with appropriate libraries in the future.

Table 3.

Example of records from the publications spreadsheet. ID = our imposed identification number (roughly alphabetical).

\begin{tabular}{|l|l|l|l|l|l|l|}
\hline ID & Author(s) & Date & Title & Journal etc. & $\begin{array}{l}\text { Volume } \\
\text { No. }\end{array}$ & $\begin{array}{l}\text { Page } \\
\text { numbers }\end{array}$ \\
\hline 1 & Abbott, J. & 1977 & $\begin{array}{l}\text { Species richness, turnover and } \\
\text { equilibrium in insular floras near } \\
\text { Perth, Western Australia. }\end{array}$ & Aust. J. Bot. & 25 & $193-208$ \\
\hline 8 & $\begin{array}{l}\text { Adams, L. D. \& } \\
\text { Craven, L. A. }\end{array}$ & 1976 & $\begin{array}{l}\text { Checklist of vascular plants in a study } \\
\text { area of the South Coast of N.S.W. }\end{array}$ & $\begin{array}{l}\text { C.S.I.R.O. Land } \\
\text { Use Res. Tech. } \\
\text { Mem. }\end{array}$ & $76 / 16$ \\
\hline
\end{tabular}




\begin{tabular}{|c|c|c|c|c|c|c|}
\hline 387 & $\begin{array}{l}\text { McMahon, A.R.G., } \\
\text { Carr, G.W., Todd, } \\
\text { J.A. \& Race, G.J. }\end{array}$ & 1990 & $\begin{array}{l}\text { The Conservation Status of Major } \\
\text { Plant Communities in Australia: } \\
\text { Victoria. }\end{array}$ & $\begin{array}{l}\text { Ecological } \\
\text { Horticulture Pty } \\
\text { Ltd, Clifton Hill, } \\
\text { Vic. }\end{array}$ & & \\
\hline 474 & Pye, K. & 1982 & $\begin{array}{l}\text { Morphology and sediments of the } \\
\text { Ramsay Bay sand dunes, } \\
\text { Hinchinbrook Island, North } \\
\text { Queensland. }\end{array}$ & Proc. R. Soc. Qld & 93 & $31-47$ \\
\hline 560 & Tate, R. & 1880 & $\begin{array}{l}\text { On the geological and botanical } \\
\text { features of southern Yorke Peninsula, } \\
\text { South Australia. }\end{array}$ & $\begin{array}{l}\text { Trans. R. Soc. S. } \\
\text { Aust. }\end{array}$ & 13 & $112-120$ \\
\hline 705 & Willis, J.H. & 1967 & $\begin{array}{l}\text { Systematic arrangement of vascular } \\
\text { plants noted on the slopes and } \\
\text { summit of the peak: The Rocks } \\
\text { Nature Reserve, New South Wales. }\end{array}$ & $\begin{array}{l}\text { Nat. Pks \& Wildl. } \\
\text { Serv., N.S.W. }\end{array}$ & 705 & \\
\hline
\end{tabular}

\section{Metadata}

The locations in this project were governed by the historical record (Table 3) and referred to one or more plant community records around a reference point. To provide a checklist for data extraction and to ensure accuracy of translation, a separate 'master site file' was created from the hard-copy printouts. This file was referenced to the digital material (source files) as they were found.

The attributes (columns) of the master site file were:

1. Formation: The high-level vegetation classification (Table 1)

2. Source file: The relevant retrieved digital file

3. Line ID Number: Site numerical identifier (if only one community per site, this was the community number)

4. Location number: Alphanumeric code for the location (State code, Table 2)

5. Community number: A sequence number for each community found at the site (1-28)

6. Locality: general description

7. State/Territory

8. Reference Number: The identification number of the associated publication (Table 3)

9. Date of reference to be used if multiple references were cited

10. Latitude and longitude: original

11. Vegetation Type 1 - the broad community description

12. Vegetation Type 2 - additional information such as dominant species or association

13. Comment line number: The line number in the source file containing comments

14. Notes from team(s) attached to the comment line. Some formations had interpretive codes for locations and sites added by the collators (Bolton 1985). These were used as keywords for sub-setting the data and as co-variates in analyses.

15. Decimal latitude and longitude

16. Coordinate uncertainty in metres 
17. Comments from retrieval team (using a consistent vocabulary).

Throughout the project there was an evolution of the fields in the master site file. In the original lists, multiple authorities were often cited, with sequential dates, one building on the work of the other or acknowledging a re-citation (an attempt to trace the provenance of a species list). Such multiple citations were not supported in Darwin Core format. Ray and Alison Specht, in consequence, reviewed all multiple author attributions and selected the most relevant to be the primary authority.

The definition of location, now possible with Geographic Positioning Systems (GPS), was not available in most of the original studies. The broad latitude and longitude information in the original datasets (Table 2) had to be updated. This need was exposed when a basic check of the resulting Darwin Core records were entered into the ALA's 'sandbox' (http:// sandbox.ala.org.au, accessed 3 May 2018) and mapped in the ALA's Spatial Portal (see Belbin 2011). All site locations were checked against the original documents where possible and verified using Google maps (satellite view). Decimal degrees columns were inserted and comments made of any amendments to an original location together with an estimate of coordinate uncertainty (Darwin Core term coordinateUncertaintylnMeters).

Several typographical and procedural inconsistencies were highlighted as the datasets were ingested. The duration of the original project — from the first datasets (late 1970s) to the last (early 1990s) - and the splicing of the data into different formations resulted in variations in the way associated information was recorded, from state/territory codes to the numbers associated with record lines for plant communities in the datasets (Table 2). These matters required reference to the original source where possible and updating the data.

When protected species are encountered in the ALA, some of their locations may be obfuscated, resulting in locational refinements being undone. The ALA's Sensitive Data Service (SDS) examines records of any sensitive species (state, territory, federal or IUCN status) and applies rules depending on the location. As these data are in the public domain, we considered it was justifiable to overrule the SDS.

\section{Species conversion file}

Full taxonomic names are used in most biodiversity information systems and analysis packages (Tokmakoff et al. 2016), and it was central to the goals of this project to turn the original alphanumeric codes into current scientific names. The first step interpreted the alphanumeric codes from the original species conversion files (Rees 2014) and the second step updated the names using the ALA's web services (Fig. 3C) Species conversion (alphacodes to names) files were developed for each vegetation formation and contained the following attributes:

1. Sequential row number

2. Validity flag: A one-character code

- $L=$ Legal (Valid) taxon 


$$
\begin{array}{ll}
\text { - } & S=\text { Synonym } \\
\text { } & M=\text { Misspelling. }
\end{array}
$$

3. Growth habit flag: one-character code based on the eco-morphological attributes listed in Table 3.2 Specht and Specht (2002)

$$
\begin{array}{ll}
\text { - } & A=\text { Aquatic } \\
\text { - } & B=\text { Semi-aquatic } \\
\text { - } & \mathrm{C}=\text { Creeper } \\
\text { - } & \mathrm{D}=\text { Dwarf shrub (sclerophyllous) }<0.25 \mathrm{~m} \\
\text { - } & \mathrm{F}=\text { Ferns } \\
\text { - } & \mathrm{G}=\text { Graminoid } \\
\text { - } & \mathrm{H}=\text { Hummock grass } \\
\text { - } & \mathrm{I}=\text { Invasive } \\
\text { - } & \mathrm{K}=\text { non-sclerophyll shrub } \\
\text { - } & \mathrm{L}=\text { Low tree } \\
\text { - } & \mathrm{M}=\text { Medium tree } \\
\text { - } & \mathrm{P}=\text { Parasite } \\
\text { - } & \mathrm{S}=\text { Shrub }>2 \mathrm{~m} \\
\text { - } & \mathrm{U}=\text { Geophytes } \\
\text { - } & \mathrm{V}=\text { Vine } \\
\text { - } & \mathrm{W}=\text { Dwarf shrub (non-sclerophyllous) }<0.25 \mathrm{~m} \\
\text { - } & \mathrm{Y}=\text { Evergreen } \\
\text { - } & \mathrm{Z}=\text { Sclerophyllous shrub }>0.25 \mathrm{~m}<2 \mathrm{~m}
\end{array}
$$

4. A general purpose code ' $G$ ', indicating stage of analysis.

5. Species code: The 9-character alphacode

6. Scientific name

At the time of the original study, a species name was updated if a new species name was identified. To retain fidelity with the original record, both names were recorded. These updates were performed by R.L. Specht as part of the original CAVE protocol (Bolton 1985, Table 4).

Table 4.

An example of the species conversion file for the sclerophyll formation and of alphacodes. This example does not illustrate the size of the files.

\begin{tabular}{|l|l|l|l|l|}
\hline $\begin{array}{l}\text { Sequential row } \\
\text { number }\end{array}$ & $\begin{array}{l}\text { Validity and } \\
\text { Growth habit flag }\end{array}$ & $\begin{array}{l}\text { Species } \\
\text { code }\end{array}$ & $\begin{array}{l}\text { Scientific name (in } \\
\text { publication) }\end{array}$ & $\begin{array}{l}\text { New Scientific name (at time } \\
\text { of original entry) }\end{array}$ \\
\hline 2 & LG & ABELMOSC & $\begin{array}{l}\text { Abelmoschus } \\
\text { moschatus }\end{array}$ & \\
\hline 14 & LZG & ACACACAN & Acacia acanthoclada & \\
\hline 19 & LMG & ACACARGY & Acacia argyrodendron & \\
\hline 20 & SZG & ACACARMA & Acacia armata & Acacia paradoxa \\
\hline 21 & MLG & ACACASHA & Acacia ashanesii & Acacia oshanesii \\
\hline
\end{tabular}




\begin{tabular}{|l|l|l|l|l|}
\hline 174 & S G & ACACKEMP & Acacia sp. aff. A. sibirica & Acacia sp. aff. A. kempeana \\
\hline 466 & S G & BORRCARP/ & $\begin{array}{l}\text { Borreria sp. aff. } \\
\text { Carpentariae }\end{array}$ & Spermacoce sp. aff. stenophylla \\
\hline 704 & S G & CARPAEQU & $\begin{array}{l}\text { Carpobrotus } \\
\text { aequilaterus }\end{array}$ & Carpobrotus modestus \\
\hline 705 & L G & CARPMODE & Carpobrotus modestus & \\
\hline 3019 & SIG & RUMEACET & Rumex acetosella & Acetosella vulgaris sens. lat. * \\
\hline 3020 & S G & RUMEANGI & Rumex angiocarpus & Acetosella vulgaris sens. lat. * \\
\hline 3647 & S & ZYGOFRUT & $\begin{array}{l}\text { Zygophyllum } \\
\text { fruticulosum }\end{array}$ & Zygophyllum aurantiacum \\
\hline 3650 & L G & ZYGOIODO & Zygophyllum iodocarpum & \\
\hline
\end{tabular}

\section{Digital processing}

The datasets in this project were large enough to preclude manual processing. As with the original study, we were therefore dependent on several computer programmes to extract, integrate and validate the data matched to Darwin Core standard terms. This process was facilitated by access to modern programming languages such as Pentaho, Java and JavaScript, utilisation of json format, and ALA web services as noted above.

\section{Species Names}

The largest problem encountered was matching the species names in the data against the National Species Lists. There will always be arguments about species identification and nomenclature. There is no universally agreed taxonomy. This phase took around half of the project programming time, even with recourse to the Australian National Species Lists (htt p://www.rbg.vic.gov.au/science/projects/taxonomy/atlas-of-living-australia-national-specieslists-project, accessed 26 June 2018). Many names had been superseded over the intervening decades. The 9-digit alphacodes, required for the original TWINSPAN analyses, presented an additional complication, since the codes were guaranteed unique only within each vegetation formation.

In many cases, the original name for the taxon had moved to a third name. In some cases, the original name was again the currently accepted name for the taxon. Splits of broadlydefined taxa e.g. Acacia aneura and Senecio lautus, into multiple taxa were mostly unresolvable into current names.

Amongst the information returned through this process were the scientific name for the taxon, its globally unique identifier, the taxon concept (essentially the name, named by and named date), common names and a match score. This ALA web service was the key component of the programme that produced a master species spreadsheet containing the best guess scientific name, taxon concept, match type and scores, source files and other 
parameters. We used five name match categories (Table 5). All results except for 'MATCH' had to be manually checked, a laborious task.

Table 5.

Species name match categories.

\begin{tabular}{|c|c|c|}
\hline CODE & Meaning & action \\
\hline MATCH & Near-exact match or better & accept \\
\hline $\begin{array}{l}\text { PARTIAL-L and } \\
\text { PARTIAL-R }\end{array}$ & A significant substring match & $\begin{array}{l}\text { manual } \\
\text { check }\end{array}$ \\
\hline FUZZY & $\begin{array}{l}\text { Fuzzy matching algorithm built on the score from the web service using a } \\
\text { 'letter-pair similarity' score }\end{array}$ & $\begin{array}{l}\text { manual } \\
\text { check }\end{array}$ \\
\hline WEAK & A weak match falling below thresholds; the best match is retained & $\begin{array}{l}\text { manual } \\
\text { check }\end{array}$ \\
\hline TAXM & No match or major problem with original or subsequent species name & $\begin{array}{l}\text { refer to } \\
\text { expert }\end{array}$ \\
\hline
\end{tabular}

This process used online and offline resources in roughly the following priority order, dependent on the nature of the uncertainty:

1. Australian Plant Census (APC: http://www.anbg.gov.au/chah/apc/index.html)

2. Australian Plant Name Index (APNI: https://biodiversity.org.au/nsl/services/apni)

3. Atlas of Living Australia (http://www.ala.org.au)

4. Google (http://www.google.com.au) and Google maps (http://maps.google.com)

5. PlantNET: NSW Flora Online Plant Name Search (http:// plantnet.rbgsyd.nsw.gov.au/ search/simple.htm)

6. FloraBase: The flora of western Australia (https://florabase.dpaw.wa.gov.au/search/ advanced)

7. Australia's Virtual Herbarium (http://avh.chah.org.au)

8. The Plant List (http://www.theplantlist.org)

9. Taxamatch: A programme for matching taxonomic names (http://biodiversity.org.au/ service/taxamatch) (Rees 2014)

10. Books and papers (e.g. Brooker and Kleinig 2004, Brooker and Kleinig 2006, Barker 2005, Barlow 1986, Cunningham et al. 1981, Erickson et al. 1979, Harden 1990, Harden 1992, Harden 1993, Harden 2002, Harden and Murray 2000, Jessop 1981, Moore 2005, Nicolle et al. 2012, Orchard 2005, Parsons and Cuthbertson 1992,Stanley and Ross 1983, Stanley and Ross 1986, Stanley and Ross 1989, Tothill and Hacker 1983).

The workflow for name resolution typically followed three stages.

\section{Stage 1: Current name check}

Often an incorrect name lookup using the ALA web service was caused by the name being misspelled in the original data, sometimes as a result of a simple typographical error. 
Taxonomists register common mistakes as 'orth. var.' and these are registered in APNI (https://biodiversity.org.au/nsl/services/apni).

The ALA name lookup sometimes returned an ambiguous result requiring further investigation. For example, Eragrostis ciliata could be mapped to E. cilianensis, E. ciliolata or Ericachne ciliata. Where only a single letter was used to represent a genus (as was occasionally the case in sequential lists in the digital master species conversion file: Table 4 ), it was necessary to manually look up the original intended genus. One then needed to go back to the start to see if the name provided a match. The absence of a name on the Australian Plant Census (APC) suggested that the Council of Heads of Australasian Herbaria (CHAH) had not resolved the taxonomy (see http://www.anbg.gov.au/chah/apc/ families-treated.html). In such cases, it came down to the best judgement using the abovelisted resources.

\section{Stage 2: Validation}

Validation was dependent on the botanical knowledge of the assessor, in this case primarily Bolton. For the cases of taxonomic splits and misapplied names, additional information was required for name resolution. If no obvious match could be found from the available resources, we checked the original data file. In cases where no clarifying information could be found, the ALA's 'Explore your area' or the ALA's Spatial Portal (http:// spatial.ala.org.au, accessed 26 June 2018) was used to identify potential candidates restricted to one or two of the original sites. Where the sites were associated with a small national park or reserve, the Spatial Portal was used to define the park or reserve as the area of interest and a species list was produced from the area report. Matches were usually found amongst the small number of species in the target genus. A good candidate species was one that was most common and occurred across the park/reserve. This strategy worked well for many taxa in south-western Western Australia.

\section{Stage 3: Reference to an expert}

Where no obvious species matches could be identified, the list of unmatched names was sent to Ray Specht, the lead author of the 1995 study (Specht et al. 1995) for resolution. Ray made determinations from his knowledge of the flora and the literature sources.

The result of this process was a master species file with 9450 taxa, mostly species names. It would be desirable to link all the species listed in this project to voucher specimens which would potentially enable the several remaining incomplete identifications (to genus, family, sp. aff. etc.) to be resolved. Comprehensively linking these records to vouchers was, however, well beyond the scope of the current project. The voucher specimens will have been deposited in relevant state and national and, possibly, international herbaria. Users may wish to pursue this if necessary and practical for repurposing. 


\section{The final data records}

The intention of this data recovery project was to enable the data to be discoverable through as many systems as possible. As the largest challenge was updating the species lists, the resources of the ALA were considered of primary importance. A set of programmes was written to interrogate:

- the master sites file,

- the species conversion files,

- the site $x$ species files, and

- the master publications file

to produce the Darwin Core Records (Fig. 3).

It was not trivial to map the attributes to Darwin Core (DwC). Five main output files were created, each file containing overlapping parts of the DwC Standard, as well as additional data that were not DwC-compliant - either for debugging purposes or because there was no DwC corollary (Fig. 3). The team followed the Completeness model (https:// code.google.com/archive/p/ala-dataquality/wikis/CompletenessModel.wiki, accessed 26 June 2018) and used the Darwin Core 'event' (https://www.gbif.org/darwin-core) to ensure a link to the plot-based approach of the collection. The 47 terms used in the database, including those that had no DwC corollary, are tabulated in the Associated Data files in the KNB repository (Cons_Atlas_DwC_fields_181009.xlsx).

\section{Discussion}

This case study highlights the importance of providing for sustained data curation if we wish to expose data for maximal re-use. The recovery project was started because of the perceived value of the historic data, its national coverage, the fear of complete data loss and the continued existence of the key player in the initial exercise, Ray Specht. The estimated cost of the time the authors have spent in recovering and processing these data is minimally $\mathrm{AU} \$ 100,000$ in addition to the $\mathrm{AU} \$ 50,000$ invested by each of the funding organisations, the ALA and TERN. As a consequence of this effort and commitment, the data are now integrated with the ALA, Australia's largest repository of species observations (https://collections.ala.org.au/public/show/dr8212) and will, in the future, be delivered as plot-based data through the Eco-informatics facility of TERN. The data set is downloadable from the Knowledge Network for Biocomplexity (Specht et al. 2018; http://doi.org/10.5063/ F1QC01QK). We cannot anticipate its possible future utility (de la Mare 1997).

Even though we had access to digital data and supporting materials, a wide range of unanticipated problems were encountered. These should provide a strong warning to those active in or retired from the ecological research community. Many of the problems encountered were the result of: 
(a) technological limitations at the time of the initial project and the work therefore required to update the data and formats to suit modern requirements,

(b) changed spatial referencing between the source material and modern standards,

(c) the long time taken to complete the initial project (resulting in variations in formatting and structure of the core data),

(d) the lapse in time between the compilation in 1995 and the start of the retrieval process in 2015 (Fig. 1), and

(e) the evolution of species names.

Changes in species names were expected, but even with the recent digital tools available through the Atlas of Living Australia, bespoke programming and expert taxonomic skills, considerably more time than initially anticipated was needed to resolve ambiguities. Without the effort, expertise and persistence of the authors, the recovery would have been impossible.

The involvement of three people from the original data collection (Specht, Specht and Bolton) in the recovery effort was invaluable for the resolution of taxonomic names, understanding the nature of the overlapping files, interpreting the information recorded, and understanding how the original project had been refined as it developed. Access to the CAVE manual (Bolton 1985) provided descriptions of the various files and fields, and access to the collection of original hard-copy material enabled refinement of the information. Many of the articles referred to were otherwise unavailable either digitally or totally, or could be found only in hard copy, sometimes in only one library in the country. To reproduce the original search and compilation effort would have taken years with delays for article discovery and retrieval, quite apart from re-extraction of the data.

It is interesting to note that there is wide acceptance of the value of the systematic collection of long-term data (e.g. Müller et al. 2010), but such data are rare and often unavailable. Data collection and data collation efforts are frequently spasmodic or at best periodic; the maintenance of continuity and standards remains a challenge. The impetus to collect 'new' data with the researcher's name uniquely attached to it is strong and is fundamental to the training of most scientists. Curation of the datasets of others has not been attractive because such curation is generally inadequately valued. Without adequate evidence across time and space, however, models cannot be built to understand the effects of events like global climate change or changes in our use of the landscape.

In the open-data world, with deposition of data for public use increasingly encouraged and supported through organisations like the Atlas of Living Australia, the Terrestrial Ecosystem Research Network, Elixir (https://www.elixir-europe.org), the Research Data Alliance, DataONE and GBIF, hopefully data loss will be less likely into the future. Even so, scientists need to be trained and encouraged to take advantage of repositories, and 
sustained funding is required to support the infrastructure necessary for good data conservation outcomes.

The original project was envisioned as a stock-take of the past, and by its conversion to and storage in digital form, a resource for the future. Despite initial enthusiasm for the project, lack of subsequent funding and continuity of effort meant this resource was almost lost. This is a common story even in cases where there was more substantial initial investment (Aronova et al. 2014; Michener 2015).

As our environment and our technological sophistication change, we need to respect information as it was originally reported. An object lesson from this project is not to be scornful of the efforts of times past, but to value them for the information they provide.

Sufficient resources need to be set aside to ensure that:

(a) scientists deposit their data as closely as possible to the time of their creation in appropriate, sustainable digital repositories,

(b) the technology of repositories is updated, and

(c) the data are appropriately conserved, allowing access, while maintaining integrity.

Only thus will data be useful to a myriad of future applications. If not, the cost of recovery of data in the future will be far higher than you may imagine and may, in fact, be impossible.

\section{Acknowledgements}

As is clear from the article, this recovery project was only possible through the contribution of an array of people and organisations over a sustained period of time. This includes the initial data collectors and their organisations, funding obtained in the 1980s from a vast number of organisations listed in the Conservation Atlas and latterly material and library support from the University of Queensland and the financial and collegial support provided by the Terrestrial Ecosystem Research Network (TERN: www.tern.org.au). AS would like to thank Bob Parsons and Peter Saenger for providing critical missing data, Eric Garnier and Bill Michener for valuable comments on earlier versions of this manuscript and several people, including Siddeswara Guru, Baptiste Laporte, Todd Vision and Chris Lortie for their encouragement.

We particularly thank the late John LaSalle, Director of the Atlas of Living Australia (ALA: $\underline{w}$ ww.ala.org.au) for supporting this recovery project through funding Bryn Kingsford for coding the scripts and providing the time of Lee Belbin (Advisor to the ALA) and Miles Nicholls (the ALA's Data Manager): John had a rare understanding of the true value of these data. 


\section{Author contributions}

AS \& LB devised project, AS was primarily responsible for article.

AS, MPB, LB and RLS verified data collation, geographical and taxonomic mapping.

BK was primarily responsible for developing the code to retrieve the data from the original files and deliver in DarwinCore format.

BK and MPB monitored programme linkages.

\section{References}

- $\quad$ Aronova E, Baker KS, Oreskes N (2014) Big Science and Big Data in biology: from the International Geophysical Year through the International Biological Program to the Long Term Ecological Research (LTER) Network, 1957-Presentamore. Historical Studies of Natural Science 40 (2): 183-224. https://doi.org/10.1525/hsns.2010.40.2.183

- Bagley PR (1968) Extension of programming language concepts. University City Science Center, Philadelphia, USA.

- $\quad$ Barker WR (2005) Standardising informal names in Australian publications. Australian Systematic Botany Society Newsletter 122: 11-12. URL: http://www.anbg.gov.au/asbs/ newsletter/pdf/05-march-122.pdf

- Barlow BA (1986) Flora and Fauna of Alpine Australasia. CSIRO in association with the Australian Systematic Botany Society, Melbourne, Australia, 543 pp. [ISBN 0643040242]

- $\quad$ Belbin L (1994) PATN: Pattern analysis package: technical reference. CSIRO, Division of Wildlife Ecology, Australia.

- Belbin L (2011) The Atlas of Living Australia's spatial portal. pp. 39-43. In: Jones MB, Gries $C$ (Eds) Proceedings of the Environmental Information Management Conference 2011 (EIM 2011), Santa Barbara, September 28-29.

- $\quad$ Bergeron B (2001) Dark Ages II: when the digital data die. 1. Pearson Educational, 336 pp. [ISBN 10: 0130661074]

- Bolton MP (1985) Classification of Australian Vegetation (CAVE) Software Manual. Version A1. unpublished, Brisbane, Australia.

- $\quad$ Brooker MI, Kleinig DA (2004) Field Guide to Eucalypts. Volume 3. Northern Australia. 2nd Edition. Bloomings Books, Melbourne, Australia. [ISBN 1876473282]

- $\quad$ Brooker MI, Kleinig DA (2006) Field Guide to Eucalypts. Volume 1. South-eastern Australia. 3rd Edition. Bloomings Books, Melbourne, Australia, 356 pp. [ISBN 9781876473525]

- $\quad$ Campbell HA, Beyer HL, Dennis TE, Dwyer RG, Forester JD, Fukuda Y, Lynch C, Hindell MA, Menke N, Morales JM, Richardson C, Rodgers E, Taylor G, Watts ME, Westcott DA (2015) Finding our way: on the sharing and reuse of animal telemetry data in Australasia. Science of the Total Environment 534: 79-84. https://doi.org/10.1016/ j.scitoenv.2015.01.089 
- $\quad$ Codd EF (1970) A relational model of data for large shared data banks. Communications of the Association for Computing Machinery (ACM) 13 (6): 377-387. https://doi.org/10.1145/362384.362685

- Cunningham GM, Mulham WE, Milthorpe PL, Leigh JH (1981) Plants of Western New South Wales. N.S.W. Government Printing Office in association with the Soil Conservation Service of NSW, Australia. [ISBN 0724020039]

- $\quad$ Curty RG, Crowston K, Specht A, B.W. G, Dalton ED (2017) Attitudes and norms affecting scientists' data reuse. PLOS One 12 (12): e0189288. https://doi.org/10.1371/ journal.pone. 0189288

- de la Mare WK (1997) Abrupt mid-twentieth century decline in Antarctic sea ice extent from whaling records. Nature 389: 57-60. https://doi.org/10.1038/37956

- Ellison AM (2010) Repeatability and transparency in ecological research. Ecology 91 (9): 2536-2539. https://doi.org/10.1890/09-0032.1

- $\quad$ Erickson R, George AS, Marchant NG, Morcombe MK (Eds) (1979) Flowers and Plants of Western Australia. Reed, Sydney, Australia, 231 pp. [ISBN 058950116X]

- Fegraus E, Andelman SJ, Jones MB, Schildhauer M (2005) Maximizing the value of ecological data with structured metadata: an introduction to ecological metadata language (EML) and principles for metadata creation. Bulletin of the Ecological Society of America 86 (3): 158-168. https://doi.org/10.1890/0012-9623(2005)86

[158:MTVOED]2.0.CO;2

- $\quad$ Frankenberg J (1971) Nature Conservation in Victoria. Victorian National Parks Association, Melbourne, Australia, $145 \mathrm{pp}$.

- Garnier E, Stahl U, Laporte M, Kattge J, Mougenot I, Kühn I, Laporte B, Amiaud B, Ahrestani FS, Bönisch G, Bunker DE, Cornelissen JHC, Díaz S, Enquist B, Gachet S, Jaureguilberry P, Kleyer M, Lavorel S, Maicher L, Pérez-Harguindeguy N, Poorter H, Schildhauer M, Shipley B, Violle C, Weiher E, Wirth C, Wright IJ, Klotz S (2017) Towards a thesaurus of plant characteristics: an ecological contribution. Journal of Ecology 105: 298-309. https://doi.org/10.1111/1365-2745.12698

- Haberle SG, Bowman DM, Newnham RM, Johnston FH, Beggs PJ, Buters J, Campbell B, Erbas B, Godwin I, Green BJ, Huete A, Jaggard AK, Medek D, Murray F, Newbigin E, Thibaudon M, Vicendese D, Williamson GJ, Davies JM (2014) The macroecology of airborne pollen in Australian and New Zealand urban areas. PLOS One 9 (5): e97925. https://doi.org/10.1371/journal.pone.0097925

- Hampton SE, Strasser CA, Tewksbury JJ, Gram WK, Budden AE, Batcheller AL, Duke CS, Porter JH (2013) Big data and the future of ecology. Frontiers in Ecology and Environment 11 (3): 156-162. https://doi.org/10.1890/120103

- Harden GJ (1990) Flora of New South Wales, Vol. 1. University of New South Wales Press, Kensington, NSW, Australia.

- Harden GJ (1992) Flora of New South Wales, Vol. 3. University of New South Wales Press, Kensington, NSW, Australia.

- Harden GJ (1993) Flora of New South Wales, Vol. 4. University of New South Wales Press, Kensington, NSW, Australia.

- Harden GJ, Murray LJ (2000) Supplement to Flora of New South Wales, Vol. 1. University of New South Wales Press, Kensington, NSW, Australia.

- Harden GJ (2002) Flora of New South Wales, Vol. 2, Revised Edition. University of New South Wales Press, Kensington, NSW, Australia. 
- Heidorn PB (2008) Shedding light on the dark data in the long tail of science. Library Trends 57 (2): 280-299. https://doi.org/10.1353/lib.0.0036

- Hill MO (1979) TWINSPAN- A FORTRAN program for arranging multivariate data in an ordered two-way table by classification of the individuals and attributes. Section of Ecology and Systematics, Cornell University, Ithaca, New York, USA.

- Jessop J (1981) Flora of Central Australia. Reed and the Australian Systematic Botany Society, Sydney, Australia.

- Jetz W, McPherson JM, Guralnik R (2012) Integrating biodiversity distribution knowledge: toward a global map of life. Trends in Ecology and Evolution 27 (3): 151-159. https://doi.org/10.1016/..tree.2011.09.007

- Keniger L, Specht A (2012) Exploring interdisciplinary collaboration in Australia's ecosystem science and management community. unpublished, Brisbane, Australia. URL: http://www.aceas.org.au/index.php? option=com_content\&view=article\&id=107\&ltemid=109\#Report\%202

- Kissling WD, Ahumada JA, Bowser A, Fernandez M, Fernández N, Alonso Garcia E, Guralnick RP, N.J.B. I, Kelling S, Los W, McRae L, Mihoub J, Obst M, Santamaria M, Skidmore AK, Williams KJ, Agosti D, Amariles D, Arvanitidis C, Bastin L, De Leo F, Egloff W, Elith J, Hobern D, Martin D, Pereira HM, Pesole G, Peterseil J, Saarenmaa H, Schigel D, Schmeller DS, Segata N, Turak E, Uhlir PF, Wee B, Hardisty AR (2017) Building essential biodiversity variables (EBVs) of species distribution and abundance at a global scale. Biological Reviews 93 (1): 600-625. https://doi.org/10.1111/brv.12359

- $\quad$ Lindenmayer DB, Likens GE (2009) Adaptive monitoring: a new paradigm for long-term research and monitoring. Trends in Ecology and Evolution 24 (9): 482-486. https:// doi.org/10.1016/.t.tree.2009.03.005

- $\quad$ Lynch C (2008) How do your data grow? Nature 455 (4): 28-29. https:// doi.org/10.1038/455028a

- Martin P, Chen Y, Hardisty A (2017) Computational challenges in global environmental research infrastructures. pp. 305-340. In: Chabbi A, Loescher H (Eds) Terrestrial Ecosystem Research Infrastructures: challenges and opportunities. CRC Press, Boca Raton, Florida, USA, $534 \mathrm{pp}$.

- $\quad$ Michener WK (2015) Ten simple rules for creating a good data management plan. PLOS Computational Biology 11 (10): e1004525. https://doi.org/10.1371/ journal.pcbi.1004525

- Michener WK (2016) Advances in managing long term ecological research data. Ecological Informatics 36: 199-200. https://doi.org/10.1016/j.ecoinf.2016.11.009

- Mills JA, Teplinsky C, Arroyo B (2015) Archiving primary data: solutions for long-term studies. Trends in Ecology and Evolution 30 (10): 581-589. https://doi.org/10.1016/ j.tree.2015.07.006

- $\quad$ Mills JA, Teplitsky C, Arroyo B (2016) Solutions for archiving data in long-term studies: a reply to Whitlock et al. Trends in Ecology and Evolution 31 (2): 85-87. https:// doi.org/10.1016/..tree.2015.12.004

- Moore P (2005) A Guide to Plants of Inland Australia. New Holland Publishers, Sydney, Australia. [ISBN 9781876334864]

- Morris BD, White EP (2013) The EcoData Retriever: Improving access to existing ecological data. PLOS One 8 (6): e65848. https://doi.org/10.1371/journal.pone.0065848

- $\quad$ Müller F, Gnauck A, Wenkel K, Schubert H, Bredemeier M (2010) Theoretical demands for long-term ecological research and the management of long-term datasets. pp. 
11-26. In: Müller F, Baessler C, Schubert H, Klotz S (Eds) Long-term Ecological Research: between theory and application. Springer Netherlands, Dordrecht, 456 pp. [ISBN 978-90-481-8781-2]. https://doi.org/10.1007/978-90-481-8782-9

- $\quad$ Nicolle D, French ME, Thiele K (2012) Notes on the identity and status of Western Australian phrase names in Corymbia and Eucalyptus (Mytaceae). Nuytsia 22 (3): 93-110. URL: https://florabase.dpaw.wa.gov.au/science/nuytsia/629.pdf

- $\quad$ Nordling L (2010) Researchers launch hunt for endangered data. Nature 468: 17. https://doi.org/10.1038/468017a

- Orchard T (2005) The Australian Plant Census ('Consensus Census'). ABRS Biologue 30 URL: http://www.anbg.gov.au/chah/apc/background-orchard-2005.html

- $\quad$ Parsons MA, Duerr R, Minster J (2010) Data citation and peer review. Earth and Space Science News 91 (34): 297-298.

- Parsons WT, Cuthbertson EG (1992) Noxious Weeds of Australia. Inkata Press, Melbourne and Sydney, Australia, 692 pp. [ISBN 0909605815]

- Peterken GP (1967) Guide to the check sheet for IBP Areas. IBP Handbook 4. Blackwell Scientific, Oxford, UK, 144 pp.

- $\quad$ Phillips N (2017) Ecologists protest Australia's plans to cut funding for environmentmonitoring network. Nature 548: 381-382. https://doi.org/10.1038/nature.2017.22453

- $\quad$ Pickrell J (2017) Research cuts rile Australian ecologists. Science 357 (6352): 632-633. https://doi.org/10.1126/science.357.6352.632

- Powney GD, Isaacs N (2015) Beyond maps: a review of the applications of biological records. Biological Journal of the Linnean Society 115: 532-542. https://doi.org/10.1111/ bij. 12517

- $\quad$ Rees T (2014) Taxamatch, an algorithm for near ('Fuzzy') matching of scientific mames in taxonomic databases. PLOS One 9 (9): e107510. https://doi.org/10.1371/ journal.pone.0107510

- Reichman OJ, Jones MB, Schildhauer MP (2011) Challenges and opportunities of open data in ecology. Science 311: 703-705. https://doi.org/10.1126/science.1197962

- $\quad$ Ross D (1984) Taxon Users' Manual. Edition P-3B. CSIRONet Manual No. 6. CSIRO (Aust.) Division of Computing Research, Canberra, Australia, $174 \mathrm{pp}$.

- Schimel DS, Asner GP, Moorcroft P (2013) Observing changing ecological diversity in the Anthropocene. Frontiers of Ecology and Environment 11 (3): 129-137. https:// doi.org/10.1890/120111

- $\quad$ Sosef MS, Dauby G, Blach-Overgaard A, van der Burgt X, Catarino L, Damen T, Deblauwe V, Dessein S, Dransfield J, Droissart V, Duarte MC, Engledow H, Fadeur G, Figueira R, Gereau RE, Hardy OJ, Harris DJ, de Heij J, Janssens S, Klomberg Y, Ley AC, Mackinder BA, Meerts P, ven de Poel JL, Sonké B, Stévart T, Stoffelen P, Svenning J, Sepulchre P, Zaiss R, Weiringa JJ, Couvreur TL (2017) Exploring the floristic diversity of tropical Africa. BMC Biology 15: 15. https://doi.org/10.1186/s12915-017-0356-8

- $\quad$ Specht A, Guru S, Houghton L, Keniger L, Driver P, Ritchie E, Lai K, Treloar A (2015) Data management challenges in analysis and synthesis in the ecosystem sciences. Science of the Total Environment 534: 144-158. https://doi.org/10.1016/ j.scitotenv.2015.03.092

- Specht A, Bolton M, Kingsford B, Specht R, Belbin L (2018) Data from the Conservation Atlas of Australian Plant communities 1879-1989 (1995). Knowledge Network for Biocomplexity. URL: https://knb.ecoinformatics.org/view/doi:10.5063/F1QC01QK 
- $\quad$ Specht RL, Cleland JB (1963) Flora conservation in South Australia. 2. The preservation fo species recorded in South Australia. Transactions of the Royal Society of South Australia 85: 177-196.

- $\quad$ Specht RL, Roe EM, Boughton VH (1974) Conservation of major plant communities in Australia and Papua New Guinea. Australian Journal of Botany 4 (7): 1-667.

- $\quad$ Specht RL, Specht A, Whelan MB, Hegarty EE (1995) Conservation Atlas of Plant Communities in Australia. Southern Cross University Press in association with the Centre for Coastal Management, Lismore, NSW, Australia. [ISBN 1875855122]

- $\quad$ Specht RL, Specht A (2013) Australia: Biodiversity of Ecosystems, pp 291-306. In: Levin S (Ed.) The Encyclopedia of Biodiversity Vol. 1. Academic Press, Waltham, Massachusetts, USA, 5504 pp. [ISBN 9780123847195].

- $\quad$ Stanley TD, Ross EM (1983) Flora of South-eastern Queensland, Vol. 1. Qld Dept of Primary Industries, Brisbane, Australia.

- $\quad$ Stanley TD, Ross EM (1986) Flora of South East Queensland, Vol. 2. Qld Dept of Primary Industries, Brisbane, Australia.

- $\quad$ Stanley TD, Ross EM (1989) Flora of South East Queensland, Vol. 3. Qld Department of Primary Industries, Brisbane, Australia.

- Teal TK, Cranston KA, Lapp H, White E, Wilson G, Ram K (2015) Data carpentry: workshops to increase data literacy for researchers. International Journal of Digital Curation 10 (1): 135-143. https://doi.org/10.2218/ijdc.v10i1.351

- Tenopir C, Allard S, Douglass K, Aydinoglu AU, Wu L, Read E, Manoff M, Frame M (2011) Data Sharing by Scientists: Practices and Perceptions. PLOS One 6 (6): e21101. https://doi.org/10.1371/journal.pone.0021101

- Tokmakoff A, Sparrow B, Turner D, Lowe A (2016) AusPlots Rangelands field data collection and publication: Infrastructure for ecological monitoring. Future Generation Computer Systems 56: 537-549. https://doi.org/10.1016/j.future.2015.08.016

- Tothill JC, Hacker JB (1983) The Grasses of Southern Queensland. University of Queensland Press, Brisbane, Australia, 475 pp. [ISBN 0702218812]

- Vines TH, Albert AY, Arianne RL, de Barre F, Bock DG, Franklin MT, Gilbert KJ, Moore J, Renaut S, D.J. R (2014) The availability of research data declines rapidly with age. Current Biology 24: 94-97. https://doi.org/10.1016/j.cub.2013.11.014

- Wieczorek J, Bloom D, Guralnick R, Blum S, Döring M, Giovanni R, Robertson T, Vieglais D (2012) Darwin Core: An evolving community-developed biodiversity data standard. PLOS One 7 (1): e29715. https://doi.org/10.1371/journal.pone.0029715

- Wyborn L (2015) Special issue rescuing legacy data for future science. Geological Research Journal 6: 106-107. https://doi.org/10.1016/i.gri.2015.02.017 